\title{
New opportunity for scholars
}

\author{
Sunil Kanwar ${ }^{1}$
}

Published online: 31 January 2017

(C) The Japan Section of the Regional Science Association International 2017

The Asia-Pacific region has become increasingly central to world affairs in all its dimensions in recent decades. One important aspect of this development has begun to be its increasingly significant contribution to global scientific research in a number of diverse areas. Good quality, peer-reviewed journals play an important role in disseminating the contributions of such research, and constitute a vital part of the knowledge landscape. The addition of the Asia-Pacific Journal of Regional Science to this stable is therefore opportune and worthwhile.

In view of the excellent editorial board, and the comprehensive logistical support of a reputable publisher, this journal is likely to make steady and substantial progress in its aim of furthering scientific enquiry in its focus areas. Its wide ambit allows immense scope for scholars to develop, analyse, establish, and resolve issues of interest. Its diffuse methodological focus, in similar fashion, enables variegated research. The large and highly-qualified editorial board promises quick turn-around of the journal submissions, along with insightful and helpful refereeing.

The distinct possibility that the readership of such an all-inclusive vehicle is itself likely to be diverse, is further incentive to publish in this journal-in the longer run, one is likely to find in here not just the refined theoretical exposition of various ideas, but their empirical validation, and possibly policy implications as well. Furthermore, a journal of this sort provides researchers both the opportunity of presenting the regional perspective as well as considering the larger global context. In all, this new opportunity appears replete with potential and promise.

Sunil Kanwar

sunil_kanwar@econdse.org

1 Department of Economics, Delhi School of Economics, University of Delhi, Delhi, India 